\title{
Appraisal of soft computing techniques in prediction of total bed material load in tropical rivers
}

\author{
C K Chang, H Md Azamathulla*, N A Zakaria and A Ab Ghani \\ River Engineering and Urban Drainage Research Centre (REDAC), Universiti Sains Malaysia \\ 14300 Nibong Tebal, Pulau Pinang, Malaysia. \\ *Corresponding author. e-mail: mdazmath@gmail.com
}

\begin{abstract}
This paper evaluates the performance of three soft computing techniques, namely Gene-Expression Programming (GEP) (Zakaria et al 2010), Feed Forward Neural Networks (FFNN) (Ab Ghani et al 2011), and Adaptive Neuro-Fuzzy Inference System (ANFIS) in the prediction of total bed material load for three Malaysian rivers namely Kurau, Langat and Muda. The results of present study are very promising: FFNN $\left(R^{2}=0.958, \mathrm{RMSE}=0.0698\right)$, ANFIS $\left(R^{2}=0.648, \mathrm{RMSE}=6.654\right)$, and $\operatorname{GEP}\left(R^{2}=0.97\right.$, RMSE $=0.057)$, which support the use of these intelligent techniques in the prediction of sediment loads in tropical rivers.
\end{abstract}

\section{Introduction}

In recent years, sand mining activities in Malaysian rivers have created several issues that need urgent attention. Among them is the deterioration of river water quality, bank erosion, river bed degradation, buffer zone encroachment, etc., that is mainly due to the excessive sand extraction along river stretches. Sand and gravel has long been used as aggregate for construction of roads and buildings. Today, the demand for these materials continues to rise and therefore, the estimation of river sediment load constitutes an important issue in river engineering. In Malaysia, the main source of sand and gravel is mostly from in-stream mining. In-stream sand mining is a common practice because the mining locations are usually along the transportation route, hence reducing transportation costs. However, in-stream sand mining can damage private and public properties as well as aquatic habitats. Excessive removal of sand may significantly distort the natural equilibrium of a stream channel. By removing sediment from the active channel bed, instream mines interrupt the continuity of sediment transport through the river system, disrupting the sediment mass balance in the river downstream and inducing channel adjustments extending considerable distances beyond the extract site itself (Kondolf et al 2001). The sediment can increase the elevation of channel beds with excess sand and gravel for tens to hundreds of kilometers downstream. Such aggradation and degardation promotes the lateral migration of channels and may cause serious floods during rainstorms due to the loss of channel capacity necessary to convey floodwaters (Kisi 2005).

Currently, there are various sediment transport equations that have been developed based on different approaches to predict the total bed material load (Chang et al 2005; Ab Ghani et al 2011). Conventional approaches used in most modelling efforts begin with an assumed form of an empirical

Keywords. Alluvial channels; Sediment transport; River engineering; ANN; ANFIS; GEP. 
or analytical equation and follow with a regression analysis or curve fitting using experimental data to determine the unknown model coefficients (Sasal and Isik 2005; Ab Ghani et al 2011). Use of the conventional empirical equations is very convenient; however their major drawback is that they involve idealization, approximation and averaging of widely varying prototype conditions and could predict sediment load which may be considerably different from their actual values. It is felt that such vast differences are partly due to the complexity of the phenomenon involved and partly because of the limitation of the analytical tool commonly used by most of the earlier investigators namely, non-linear statistical regression. The present study therefore reanalyzes the past data using neural networks (Ab Ghani et al 2011) and genetic programming techniques (Zakaria et al 2010).

Although a number of successful attempts have been recorded by Dogan et al (2007); Azamathullah and Deo (2008); Guven (2009) and Azamathulla et al (2009), a wider application of theoretical models is restrained by their heavy demand in terms of computing capacity and time. Alternatively, soft computing techniques, such as neural networks, evolutionary computation, fuzzy logic and genetic programming have been successfully applied in water engineering problems since the last two decades (Nagy et al 2002; Kisi 2005; Kisi et al 2006; Aytek and Kisi 2008; Yang et al 2009). A wider application of theoretical models is restricted by their heavy demand in terms of computing capacity and time (Dogan et al 2009).

Feed forward neural networks (FFNN) technique and adaptive neuro-fuzzy inference system (ANFIS) and genetic expression programming (GEP) techniques were considered in the present study. Use of the neural network tool box under the MATLAB software has been made in the present study. The function 'genfis1' (genfis1 generates a Sugeno-type FIS structure used as initial conditions, i.e., initialization of the membership function parameters for anfis training) involved in the ANFIS provides an efficient design which produced acceptable results (Kisi 2007) and hence, the same was employed herein. Similarly the 'genfis2' (genfis2 generates a Sugeno-type FIS structure using subtractive clustering and requires separate sets of input and output data as input arguments. When there is only one output, genfis 2 may be used to generate an initial FIS for anfis training; genfis2 accomplishes this by extracting a set of rules that models the data behaviour) code that generates the first order Sugeno fuzzy system based on the subtractive clustering of datasets has been used to develop the ANFIS system. A GEP software, GPLAB in conjunction with subroutines coded in MATLAB were used to develop GEP model.

\section{Methodologies for soft computing techniques}

\subsection{Neural networks}

Neural networks (NNs) technique is a data processing tool that mimics the function of the human brain and nerves built on the so-called neurons - processing elements - connected to each other. Artificial neurons are organized in such a way that the structure resembles a network. This technique differs from the traditional data processing; it studies the relationship between the input and output data (Azmathullah et al 2005).

The basic element of NNs is an artificial neuron, which consists of three main components; weights, bias, and an activation function. Each neuron receives inputs $x_{i}(i=1,2, \ldots, n)$ attached with a weight $w_{i j}(j \geq 1)$ which shows the connection strength for a particular input for each connection. Every input is then multiplied by the corresponding weight of the neuron connection and is summed as:

$$
W_{i}=\sum_{j=1}^{n} w_{i j} x_{j} .
$$

A bias $b_{i}$, a type of correction weight with a constant non-zero value, is added to the summation $(U)$ in equation (1) as:

$$
U_{i}=W_{i}+b_{i}
$$

In other words, $W_{i}$ in equation (1) is the weighted sum of the $i$ th neuron for the input received from the preceding layer with $n$ neurons, $w_{i j}$ is the weight between the $i$ th neuron in the hidden layer and the $j$ th neuron in the preceding (input) layer, and $x_{j}$ is the output of the $j$ th neuron in the input layer. After being corrected by a bias as in equation (2), the summation is transferred using a scalarto-scalar function called an 'activation or transfer function', $f\left(U_{i}\right)$, to yield a value called the unit's 'activation', given as:

$$
y_{i}=f\left(U_{i}\right) .
$$

Readers can refer to other previously published works on scouring around and downstream of hydraulic structures such as Liriano and Day (2001), Azamathulla and Ab Ghani (2010).

\subsection{FFNN}

Artificial neural networks (ANN) have been successfully used in river flow forecasting (Aqil et al 2007; Firat and Turan 2010), rainfall-runoff modelling (Antar et al 2006) and water level fluctuations (Altunkaynak 2007). Typically, ANN are 


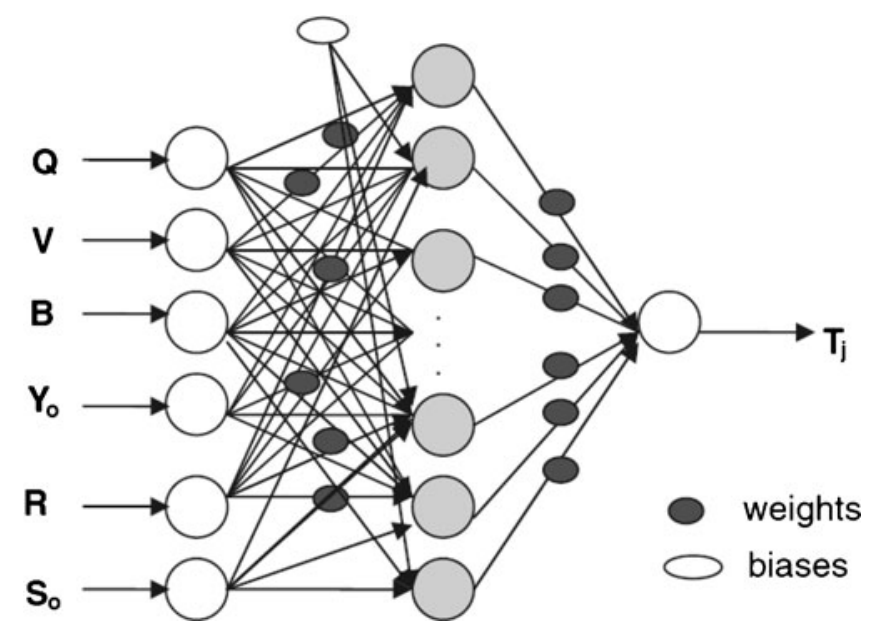

Figure 1. Feed forward neural network model (Ab Ghani et al 2011).

adjusted or trained, so that a particular input leads to a specific target output. ANN are good at fitting functions, reorganizing patterns and clustering data (Demuth et al 2007).

Ab Ghani et al (2011) applied the configuration of a typical three-layer neural network, which consists of an input layer, a hidden layer, and an output layer as shown in figure 1 . The basic idea of the neural network can be described as following: First, a set of data $\left(Q, V, B, Y_{o}, R, S_{o}\right)$ as raw information is fed into the network at the input layer; then, the neural network will be trained and the complex relationship between inputs and output $\left(T_{j}\right)$.

\subsection{ANFIS}

The adaptive neuro-fuzzy inference system (ANFIS) on the other hand is a hybrid scheme which uses the learning capability of the ANN to derive the fuzzy if-then rules with appropriate membership functions worked out from the training pairs leading finally to the inference. The difference between the common neural network and the ANFIS is that while the former captures the underlying dependency in the form of the trained connection weights, the latter does so by establishing the fuzzy language rules. The input in ANFIS (figure 2) is first converted into fuzzy membership functions, which are combined together, and after following an averaging process, used to obtain the output membership functions and finally the desired output.

\subsection{GEP}

Gene-expression programming (GEP), an extension to genetic programming (GP) (Koza 1992), is a search technique that evolves computer programs (mathematical expressions, decision trees, polynomial constructs, logical expressions, and so on). The computer programs of GEP are all encoded in linear chromosomes, which are then expressed or translated into expression trees (ETs). ETs are sophisticated computer programs that are usually evolved to solve a particular problem, and are selected according to their fitness at solving that problem. Thanks to genetic modification, population of ETs will discover traits and therefore will adapt to the particular problem they are employed to solve. This means that, within the stipulated time and setting the stage correctly, a good solution to the problem will be discovered (Ferreira 2001a, 2001b).

GEP is a full-fledged genotype/phenotype system, with the genotype totally separated from the phenotype, while in GP, genotype and phenotype are one entangled mess or more formally,

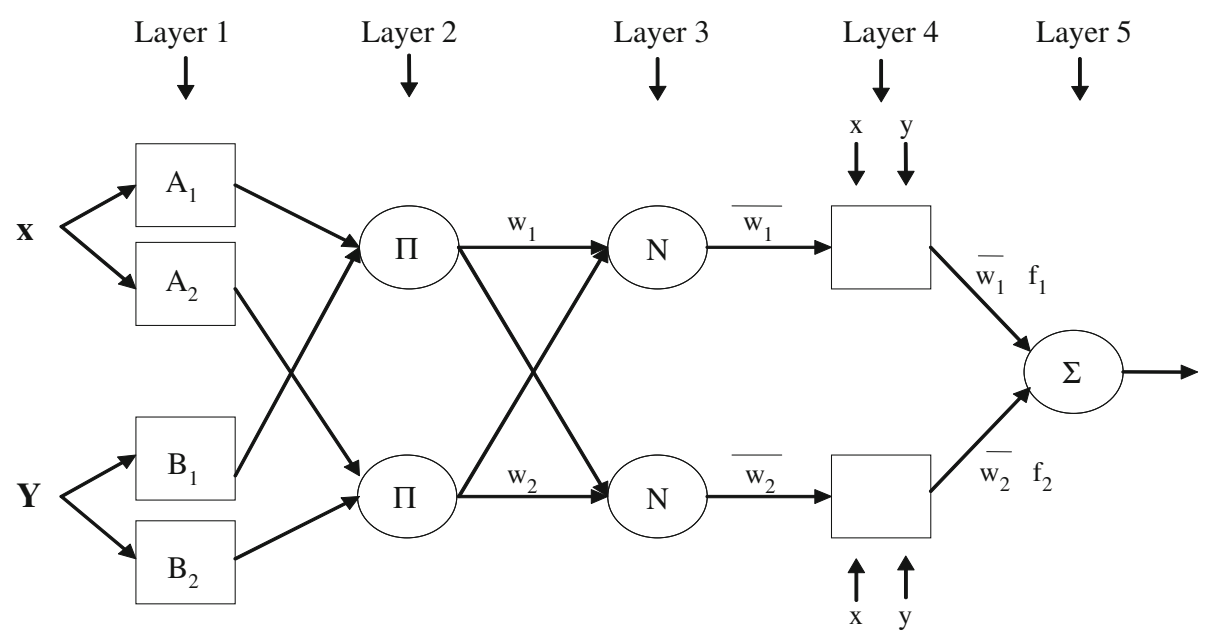

Figure 2. ANFIS network architecture. 
a simple replicator system. As a consequence of this, the full-fledged genotype/phenotype system of GEP surpasses the old GP system by a factor of 100-60,000 (Ferreira 2001a, 2001b).

Initially, the chromosomes of each individual of the population are randomly generated. Then the chromosomes are expressed and each individual is evaluated based on a fitness function, and selected to reproduce with modification, leaving progeny with new traits. The individuals of new generation are, in turn, subjected to some developmental processes such as expression of the genomes, confrontation of the selection environment, and reproduction with modification. These processes are repeated for a predefined number of generations or until a solution is achieved (Ferreira 2001a, 2001b; Guven and Aytek 2009; Zakaria et al 2010).

\section{Study area and data used}

In Malaysia, the main source of sand is mostly from in-stream mining. Therefore, the present study covers six sites at each of the three rivers, i.e., Kurau, Langat and Muda that have different levels of sand mining activities (figure 3). Fewer activities of sand mining are on-going in Kurau River at the upstream of Bukit Merah Reservoir. Langat River recently has been a major source of sand for construction with the development of Putrajaya. Muda River has a long history of sand mining activity along the upper reach.

The surveyed cross sections for the Muda and Langat rivers are single thread channels with the top width ranging between 22.5 and $134.0 \mathrm{~m}$, representing medium-sized rivers, and the top width
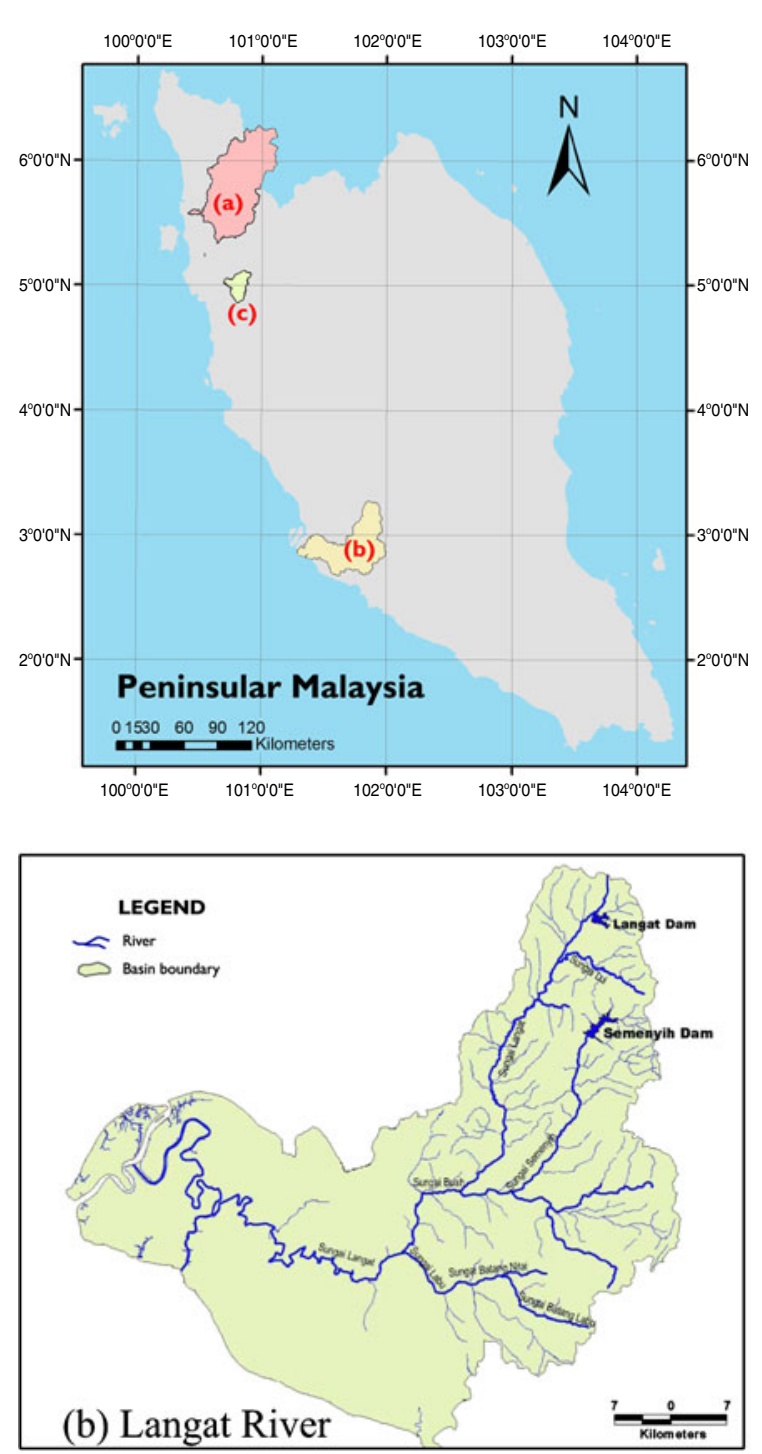
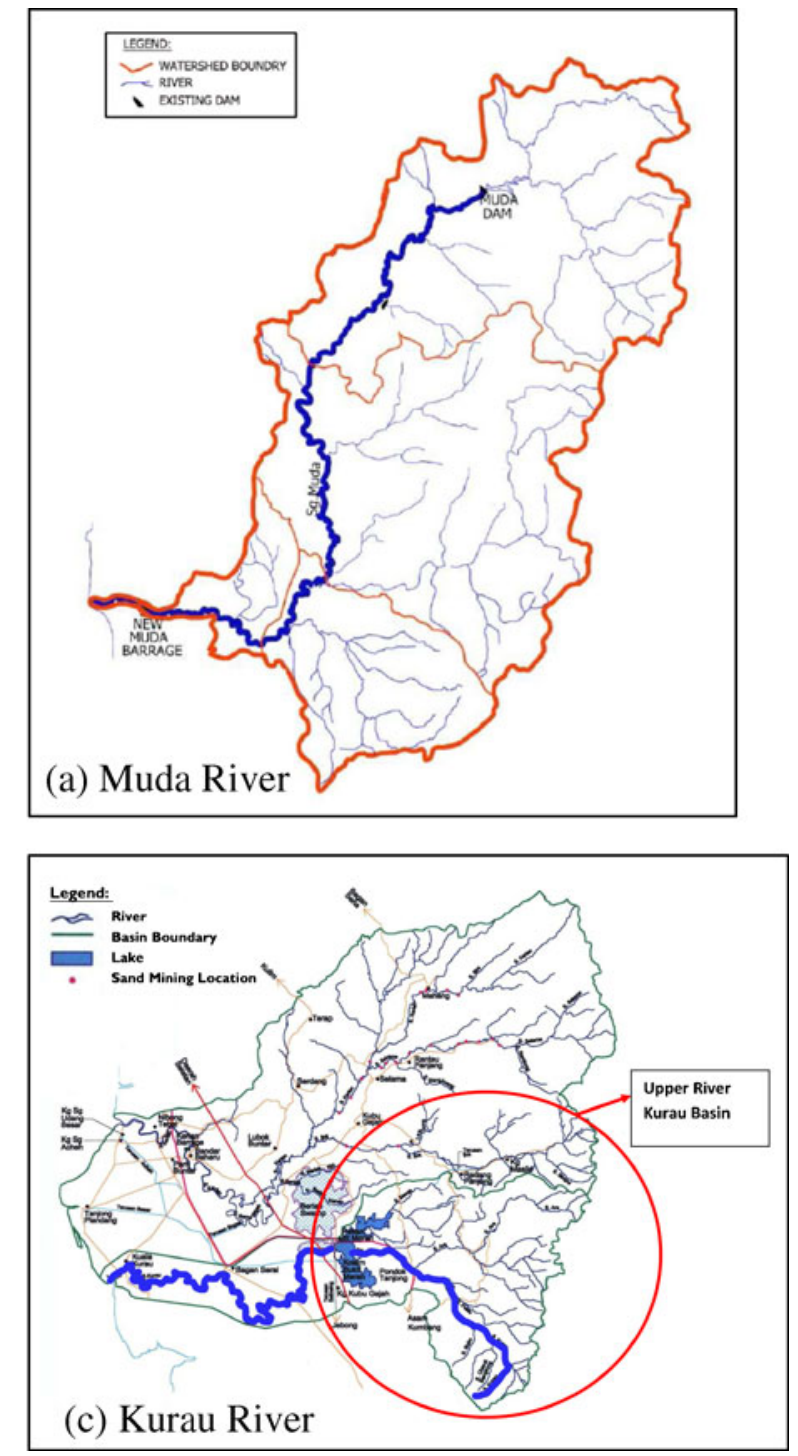

Figure 3. Study area (location of three rivers). 
Table 1. Range of field data for Kurau, Langat and Muda rivers.

\begin{tabular}{lrrr}
\hline & \multicolumn{3}{c}{ Study area } \\
\cline { 2 - 4 } Parameters & \multicolumn{1}{c}{ Kurau River } & Langat River & \multicolumn{1}{c}{ Muda River } \\
\hline Flow discharge, $Q\left(\mathrm{~m}^{3} / \mathrm{s}\right)$ & $0.63-28.94$ & $2.75-120.76$ & $2.59-343.71$ \\
Flow velocity, $V(\mathrm{~m} / \mathrm{s})$ & $0.27-1.12$ & $0.23-1.01$ & $0.14-1.45$ \\
Water-surface width, $B(\mathrm{~m})$ & $6.30-26.00$ & $16.4-37.6$ & $9.0-90.0$ \\
Flow depth, $Y_{o}(\mathrm{~m})$ & $0.36-1.91$ & $0.64-5.77$ & $0.73-6.90$ \\
Cross sectional area of flow, $A\left(\mathrm{~m}^{2}\right)$ & $1.43-33.45$ & $8.17-153.57$ & $5.12-278.34$ \\
Hydraulic radius, $R(\mathrm{~m})$ & $0.177-1.349$ & $0.45-3.68$ & $0.55-3.90$ \\
Channel slope, $S_{o}$ & $0.00050-0.00210$ & $0.00065-0.00185$ & $0.00008-0.000235$ \\
Bed load, $T_{b}(\mathrm{~kg} / \mathrm{s})$ & $0.080-0.488$ & $0.027-0.363$ & $0-0.191$ \\
Suspended load, $T_{t}(\mathrm{~kg} / \mathrm{s})$ & $0.001-2.660$ & $0.2860-99.351$ & $0.024-15.614$ \\
Total bed material load, $T_{j}(\mathrm{~kg} / \mathrm{s})$ & $0.089-2.970$ & $0.525-99.398$ & $0.099-15.644$ \\
Median sediment size, $d_{50}(\mathrm{~mm})$ & $0.41-1.90$ & $0.31-3.00$ & $0.29-2.10$ \\
Manning's $n$ & $0.014-0.066$ & $0.034-0.195$ & $0.021-0.108$ \\
\hline
\end{tabular}

Table 2. Discrepancy ratio for three rivers using Yang and Engelund-Hansen equations.

\begin{tabular}{lcccccc}
\hline & & \multicolumn{3}{c}{ Discrepancy ratio (DR) between 0.5 and 2.0 } \\
\cline { 3 - 4 } & & \multicolumn{2}{c}{ Yang equation } & \multicolumn{2}{c}{ Engelund-Hansen equation } \\
\cline { 3 - 4 } Location & Total data & No. of data & $\%$ & & No. of data & $\%$ \\
\hline Kurau River & 78 & 33 & 42.31 & 38 & 48.72 \\
Langat River & 60 & 30 & 50.00 & 31 & 51.67 \\
Muda River & 76 & 16 & 21.05 & 19 & 25.00 \\
& 214 & 79 & 36.92 & 88 & 41.12 \\
\hline
\end{tabular}

for Kurau River ranges between 25.8 and $41.0 \mathrm{~m}$, representing a small-medium river. The slopes are between 0.00008 and 0.0021 , indicating that the cross sections are still natural (Ab Ghani et al 2003). The details of the morphological and hydrological descriptors and range of field data are given in table 1. Details of the measurement methodology are given in Ab Ghani et al (2003). The data collection includes flow discharge $(Q)$, bed load $\left(T_{b}\right)$ and water surface slope $\left(S_{o}\right)$. In addition, the bed elevation, water surface and thalweg measurement (the minimum bed elevation for a cross section) were also determined at the selected cross sections. The total bed material load $\left(T_{j}\right)$ is composed of the suspended load and bed load. The total bed material load must be specified for sediment transport, scour and deposition analysis.

\section{Sediment transport equations assessment}

A detailed sediment transport study at six sites for each river was conducted and it was found that from the previous studies (Ab Ghani et al 2003; Ariffin et al 2008; Chang et al 2008), Yang and Engelund-Hansen equations are the best existing equations to predict the trend of sediment transport for the Malaysian rivers (Ab Ghani et al 2011).

Yang (1972) related the bed material load to the rate of energy dissipation of the flow as an agent for sediment transport. The theory of minimum rate of energy dissipation states that when a dynamic system reaches its equilibrium condition, its rate of energy dissipation is at a minimum. The minimum value depends on the constraints applied to the system. Engelund and Hansen (1967) applied Bagnold's stream power concept and the similarity principle to derive the sediment transport function. Engelund and Hansen equation can be used in both dune bed forms and upper regime (plane bed) with mean sediment size $\left(d_{50}\right)$ larger than $0.15 \mathrm{~mm}$.

The assessments of two existing sediment transport equations, the Yang (1972) and EngelundHansen (1967) equations were performed for the 214 sets of data for present study (table 1). The performances of the equations were measured using the discrepancy ratio (DR), which is the ratio of the estimated load to the measured load (DR = estimated/measured). As applied in most sediment transport studies (Yang 1972; Yang et al 2009), a discrepancy ratio of $0.5-2.0$ was used as a criterion in the evaluation of the selected equations. 
The evaluation using these equations shows that both equations, in most cases, overestimated the measured values, as shown in table 2 .

\section{Implementation of the soft computing techniques}

The nature and motivation of traditional total bed material load models differ significantly. These approaches are normally able to make predictions within about one order of magnitude of the actual measurements. To overcome the complexity and uncertainty associated with total-load estimation, this research demonstrates that soft computing techniques can be applied for accurate prediction of total bed material load transport. The present study summarizes the recent results based on field data collected at three river catchments in Malaysia, i.e., the Kurau, Langat and Muda rivers (DID 2009).

\subsection{ANFIS}

In the present study, the usual ANFIS network was considered (figure 4). It was trained using both genfis1 and genfis2, as well as ANFIS with different radii to ensure that proper training is imparted. Further, in order to see if advanced training schemes (GEP) provide better learning than the basic feed forward back propagation network. In the ANFIS model use of input variables, the input was changed to single and the output was the relative total bed material load $\left(T_{j}\right)$.

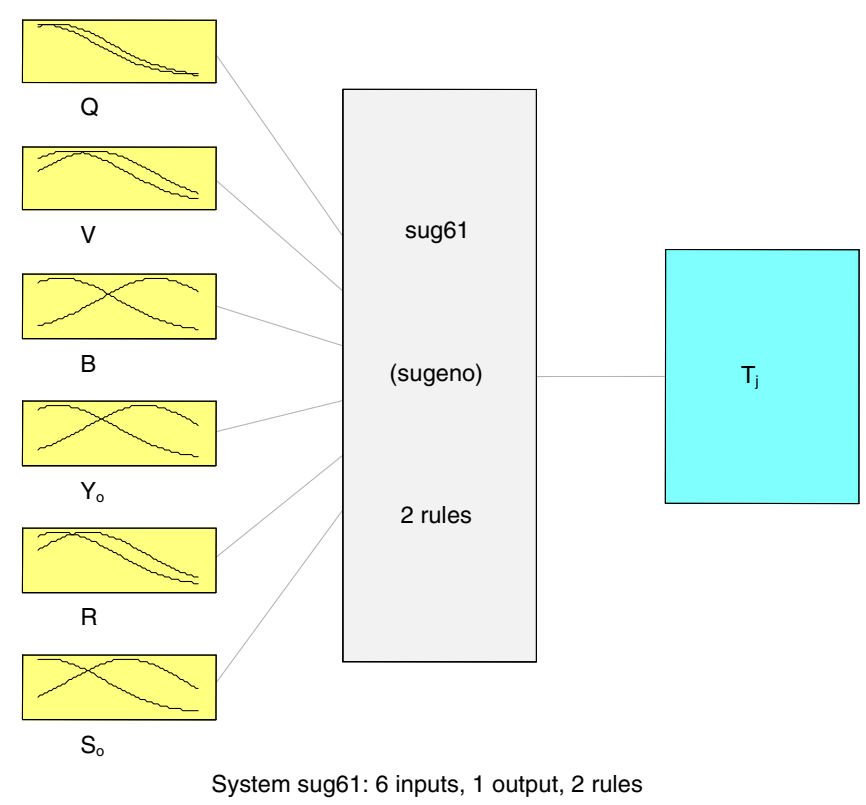

Figure 4. ANFIS model for total bed material load in rivers.
After the input and output parameters were determined, genfis2 was employed to generate first-order Sugeno fuzzy system and the ANFIS architectures are similar as they have the same number of inputs and rules. ANFIS model employs the input variables namely, $Q, V, B, Y_{o}, R$ and $S_{o}$ and results the output of total bed material load, respectively.

A total of 214 input-output pairs, $80 \%$ were randomly selected and were used for training and the remaining $20 \%$ of values were used for testing or validation, dictated by the use of Gaussian function. All patterns were normalized within the range of $0.0-1.0$ before their use. The trainings of these networks were stopped after reaching the minimum error goal of 0.0001 (MATLAB 2007).

\subsection{GEP}

A GEP technique, which is an extension to GP, used computer programs all encoded in linear chromosomes, which are then expressed or translated into expression trees (ETs). ETs are sophisticated computer programs that are usually used to solve a particular problem and are selected according to their fitness at solving that problem. Once the training set was selected, one could say that the learning environment of the system is defined. A population of candidate chromosomes (programs) is created and then each program is tested against a pre-defined fitness (error) criterion.

It should be noted that the proposed GEP formulations in equation (4) (Zakaria et al 2010) is valid for total bed material load variables ranging between minimum and maximum values given in table 3. Examination of table 3 for the case of total bed material load suggests that there is a large variation in magnitudes of error measures across the neural networks and that the most accurate network is the FFNN Model (Ab Ghani et al 2011), the coefficient of determination $R^{2}, 0.958$ and the RMSE 0.0698 of the ANN method are higher than those of the traditional method.

The best of generation individual, chromosome 10, has fitness 470 for this GEP modelling of sediment transport (Zakaria et al 2010). The explicit formulations of GEP for total bed material load,

Table 3. Comparison of network - yielded and true values.

\begin{tabular}{lccr}
\hline Model & CPU time & $R^{2}$ & RMSE \\
\hline GEP & $48 \mathrm{~h}$ & 0.97 & 0.057 \\
FFNN & $30 \mathrm{~min}$ & 0.958 & 0.0698 \\
Yang (1973) & - & 0.722 & 10.376 \\
Engelund-Hansen (1967) & - & 0.623 & 12.735 \\
ANFIS & $20 \mathrm{sec}$ & 0.648 & 6.654 \\
\hline
\end{tabular}


as a function of $Q, V, B, Y_{o}, R, S_{o}, W s, d_{50}$, were obtained as:

$$
\begin{aligned}
T_{j}= & {\left[\left(-0.39 * R Y_{0} * \sqrt{S_{0}}\right) /\left(-0.72+S_{0}\right)\right] } \\
& +\left(R+e^{\sin (Q V R)}\right)+\operatorname{Tan}^{-1}(-0.16 * R B) \\
& +R \sqrt{Q})+\left(d_{50}-3.39\right) * d_{50}^{3} * S_{0} \\
& +\operatorname{Tan}^{-1}(V) * e^{V}-\log \left(6.93-Y_{0}\right) \\
& *((W s * B) /(-2.075)) .
\end{aligned}
$$

\section{Result and discussion}

The performance of the ANFIS model in predicting the total bed material load transport for all the measured data after removing outliers were measured using the discrepancy ratio values, which is the ratio of the predicted load to measured load. From the analysis, the performance of the model was assessed by evaluating the scatter plots between the observed and predicted results (figure 5). The model has produced an average discrepancy ratio greater than 5 with the low coefficient of determination $\left(R^{2}\right)$ of 0.648 and root mean squared error (RMSE) of 6.654. A comparison result was made with earlier ANN results using FFNN and GEP (table 3 ). The FFNN has yielded an $R^{2}$ of 0.958 and an RMSE of 0.0698 (Ab Ghani et al 2011) whilst, GEP yielded an $R^{2}$ of 0.97 and an RMSE of 0.057 (Zakaria et al 2010) respectively. Using the FFNN and GEP network, the computed total load transport rates were in much closer agreement.

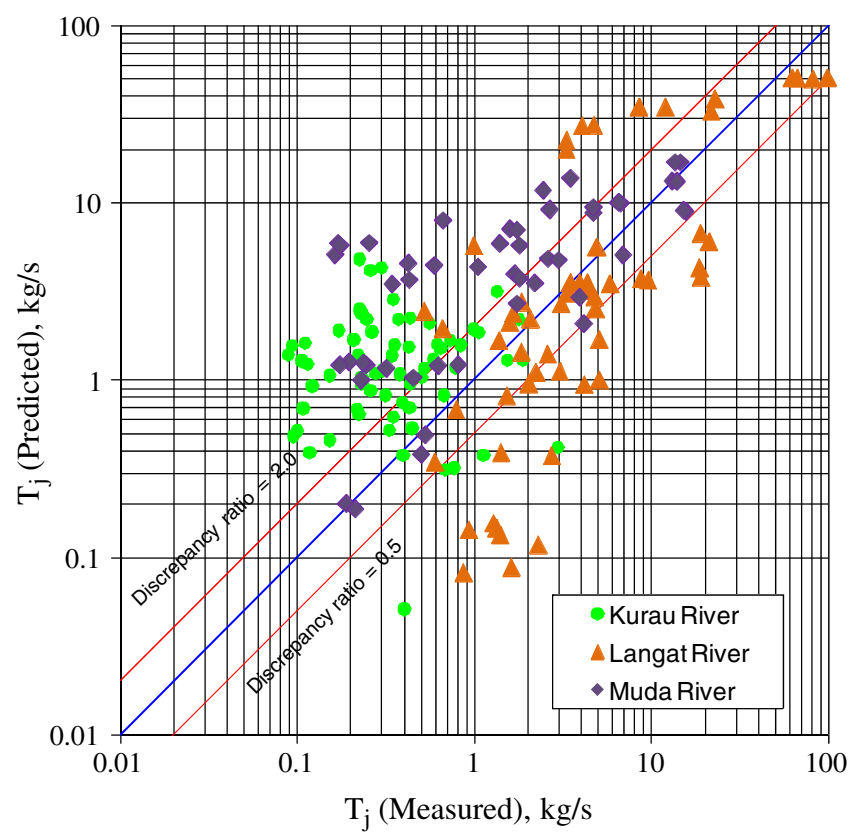

Figure 5. Predicted using ANFIS against observed total bed material load.
The results show that there is an excellent agreement between the FFNN and GEP models only and these models have predicted values with the lowest errors. Also, besides high accuracy, the calculation speed of the proposed models to obtain the results is important. On the same workstation, the simulation time for obtaining total bed material load was measured for the ANFI, FFNN and GEP models (table 3 ). The result shows that ANFIS is able to complete the training within 20 seconds (CPU time) while FFNN and GEP have taken more CPU time compared to ANFIS. Using the same input data for the predicting total bed material load transport, it is clear that the ANFIS model is much faster than FFNN and GEP models, but it does not perform well in predicting total bed material load transport compared to GEP (Zakaria et al 2010) and FFNN (Ab Ghani 2011). As a result, GEP which is able to produce a simple formula with a mathematical function to fit to given observed sediment data and yield higher accuracy is recommended in this research.

For practical problems, using an easy method, which is usable for different cases, is more acceptable than traditional methods. Also, using low cost public domain software (QNET software) would be more satisfactory for researchers and engineers, especially for students, instead of costly softwares like MATLAB, GPLAB and Neuro Solutions. However, sensitivity and performance of the model need to be tested and evaluated with the input data so that the goal of the procedure to evolve the best agreement with the lower errors function that will fit to the data is achieved.

\section{Conclusions}

In this study, the performance of three soft computing techniques, namely FFNN, ANFIS and GEP, was evaluated in prediction of total bed material load. Actual filed measurements were used in calibration and testing the proposed models. A common application of the different error criteria indicated an overall best performance of the GEP in this particular mapping problem. The treatment to non-linearities in the sediment load data meted out by the GEP approach worked much better than ANFIS and FFNNs (black box models). The results were compared with the sediment transport equations, ANFIS and neural network scheme; it was found that although the CPU time of GEP is longer, it is highly satisfactory and performs well in predicting total bed material load transport. This study also shows that soft computing techniques are efficient tools to predict total bed material load more accurately for the Malaysian rivers. 


\section{Acknowledgements}

The analysis was carried out at the River Engineering and Urban Drainage Research Centre (REDAC), Universiti Sains Malaysia in Nibong Tebal, Malaysia. Support from the Department of Irrigation and Drainage Malaysia (CRNo. JPS(PP)/SG/05/07) is gratefully acknowledged. The authors also wish to express their sincere gratitude to Universiti Sains Malaysia for a research university grant to conduct this on-going research (PRE .1001/PREDAC/811077) led by the second author.

\section{Notations}

$\begin{array}{ll}b & \text { bias } \\ B & \text { river width } \\ d_{50} & \text { mean sediment size } \\ Q & \text { flow discharge } \\ R & \text { hydraulic radius } \\ R^{2} & \text { coefficient of determination } \\ S_{o} & \text { water surface slope } \\ T_{b} & \text { bed load } \\ T_{j} & \text { total bed material load } \\ T_{s} & \text { suspended load } \\ U & \text { summation of weighted input and bias } \\ \mathrm{V} & \text { average flow velocity } \\ W & \text { weighted input } \\ W s & \text { fall velocity of the sediment particle } \\ Y_{o} & \text { flow depth }\end{array}$

\section{References}

Ab Ghani A, Azamathulla H Md, Chang C K, Zakaria N A and Abu Hasan Z 2011 Prediction of total bed material load for rivers in Malaysia: A case study of Langat, Muda and Kurau rivers; J. Environ. Fluid Mechanics 11(3) 307-318.

Ab Ghani A, Zakaria N A, Abdullah R, Chang C K, Sinnakaudan S K and Mohd Sidek L 2003 Guidelines for field data collection and analysis of river sediment, Malaysia, Kuala Lumpur: Department of Irrigation and Drainage, 35p.

Altunkaynak A 2007 Forecasting surface water level fluctuations of Lake Van by Artificial Neural Networks; Water Resour. Manag. 21(2) 399-408.

Antar M, Elassiouti I and Allam M 2006 Rainfall-runoff modelling using artificial neural networks technique: A Blue Nile catchment case study; Hydrol. Process. 20(5) 1201-1216.

Aqil M, Kita I, Yano A and Nishiyama S 2007 Neural networks for real time catchment flow modelling and prediction; Water Resour. Manag. 21(10) 1781-1796.

Ariffin J, Ahmad Kamal N, Sa'adon M S, Taib M N, AbdulTalib S, Ab Ghani A, Zakaria N A and Yahaya A S 2008 Sediment model for natural and man-made channels using general regression neural network; Journal of the Institution of Engineers, Malaysia 69(3) 44-58.
Aytek A and Kisi O 2008 A genetic programming approach to suspended sediment modeling; J. Hydrol. 351(3-4) $288-298$.

Azamathulla H Md and Ab Ghani A 2010 Genetic programming to predict river pipeline scour; J. Pipeline Syst. Eng. Pract. 1(3) 127-132.

Azamathulla H Md, Chang C K, Ab Ghani A, Abu Hasan Z and Zakaria N A 2009 An ANFIS-based approach for predicting the bed load for moderately-sized rivers; $J$. Hydro-environment Res. 3(1) 35-44.

Azamathulla H Md, Deo M C and Deolalikar P B 2005 Neural networks for estimation of scour downstream of a flip bucket; J. Hydraul. Eng. 131(10) 898-908.

Azamathulla $\mathrm{H}$ Md, Deo M C and Deolalikar P B 2008 Alternative neural networks to estimate the scour below spillways; Advances in Engineering Software 39(8) 689-698.

Chang C K, Ab Ghani A, Abdullah R and Zakaria N A 2008 Sediment transport modeling for Kulim river - A case study; J. Hydro-environment Res. 2(1) 47-59.

Chang C K, Ab Ghani A, Zakaria N A, Abu Hasan Z and Abdullah R 2005 Sediment transport equation assessment for selected rivers in Malaysia; Int. J. River Basin Manag. 3(3) 203-208.

Demuth H, Beale M and Hagan M 2007 Neural Network Toolbox 6, Users Guide; The MathWorks Inc., Natick, M.A.

Department of Irrigation and Drainage Malaysia (DID) 2009 Study on River Sand Mining Capacity in Malaysia; DID, Kuala Lumpur.

Dogan E, Yüksel I and Kisi O 2007 Estimation of total sediment load concentration obtained by experimental study using artificial neural networks; Environ. Fluid Mechanics 7(4) $271-288$.

Dogan E, Tripathi S, Lyn D A and Govindaraju R S 2009 From flumes to rivers: Can sediment transport in natural alluvial channels be predicted from observations at the laboratory scale?; Water Resour. Res. 45(8) W08433.

Engelund F and Hansen E A 1967 Monograph on sediment transport in alluvial streams; Copenhagen, Denmark: Teknisk Forlag.

Ferreira C 2001a Gene expression programming in problem solving; 6th Online World Conference on Soft Computing in Industrial Applications (invited tutorial).

Ferreira C 2001b Gene expression programming: A new adaptive algorithm for solving problems; Complex Syst. 13(2) $87-129$.

Firat M and Turan E 2010 Monthly river flow forecasting by an Adaptive Neuro-Fuzzy Inference System; Water Environ. J. 24(2) 116-125.

Guven A 2009 Linear genetic programming for time-series modelling of daily flow rate; J. Earth Syst. Sci. 118(2) $137-146$.

Guven A and Aytek A 2009 A new approach for stagedischarge relationship: Gene-Expression Programming; $J$. Hydrol. Eng. 14(8) 812-820.

Kisi O 2005 Suspended sediment estimation using neurofuzzy and neural network approaches; Hydrol. Sci. 50(4) 683-696.

Kisi O 2007 Evapotranspiration modelling from climatic data using a neural computing technique; Hydrol. Process. 21(4) 1925-1934.

Kisi O, Karahan M E and Sen Z 2006 River suspended sediment modelling using a fuzzy logic approach; Hydrol. Process. 20(20) 4351-4362.

Kondolf G M, Smeltzer M and Kimball L 2001 Freshwater Gravel Mining and Dredging Issues; Washington Departments of Fish and Wildlife, Ecology, and Transportation, Olympia. 
Koza J R 1992 Genetic programming: On the programming of computers by means of natural selection; A Bradford Book, MIT Press.

Liriano S L and Day R A 2001 Prediction of scour depth at culvert outlets using neural networks; J. Hydroinformatics 3(4) 231-238.

MATLAB 2007 Neural network tool box version 5.0. The Math-Works Inc., Matick, Mass.

Nagy H M, Watanabe K and Hirano M 2002 Estimation of sediment load concentration in rivers using artificial neural network model; J. Hydraul. Eng. 128(6) 588-595.

Sasal E M D and Isik S 2005 Suspended sediment load estimation in lower Sakarya river by using soft computational methods; Proceeding of the International Conference on Computational and Mathematical Methods in Science and Engineering, CMMSE 2005, Alicante, Spain, pp. 395-406.

Yang C T 1972 Unit stream power and sediment transport; J. Hydraulics Division 98(10) 1805-1826.

Yang C T, Reza M and Aalami M T 2009 Evaluation of total load sediment transport using ANN; Int. J. Sedim. Res. 24(3) 274-286.

Zakaria N A, Azamathulla H Md, Chang C K and Ab Ghani A 2010 Gene expression programming for total bed material load estimation - a case study; Science of the Total Environment 408(21) 5078-5085. 